\title{
Analysis of a new solar chimney plant design for mountainous regions
}

\author{
M. A. Serag-Eldin \\ Mechanical Engineering Department, \\ American University in Cairo, Egypt
}

\begin{abstract}
The paper presents a new design for solar chimney plants to be erected on mountainous terrain. The objective is to exploit the height of nearby mountains to replace the conventional vertical chimney by a duct built over the steep side of the mountain. The concept is evaluated here employing a computational model involving three-dimensional governing equations, describing mass, momentum and energy balances, in addition to transport of two turbulence quantities. A typical application is demonstrated for a $45^{\circ}$ sloped mountain. The concept is shown to be plausible and offers many advantages over conventional chimney designs.

Keywords: solar chimneys, solar energy, renewable energy, buoyancy driven flows, solar power plants.
\end{abstract}

\section{Introduction}

The present paper introduces a modification to the conventional solar chimney plant in order to exploit the available heights of any nearby available mountain. The new design is evaluated by means of a suitable mathematical model. The paper starts in this section by describing the conventional solar chimney plant and then introducing the suggested design modifications. The next section presents the adopted mathematical model. The model is then applied to predict the flow field and performance of a demonstration case, and the results are displayed and discussed. The advantages of the new design are listed, and finally, a summary and conclusions is presented. 


\subsection{Conventional solar-chimney plant}

Solar-chimney power plants are renewable energy devices which generate mechanical power from solar energy after first converting it into wind energy. They comprise a tall chimney stack located at the center of a giant solar energy collector displaying an elevated glass roof, covering a large area of ground clad with a suitable absorber material. Figure 1 displays a cross-sectional sketch of a typical plant; the arrows point to the main direction of flow, and the label "W.T." points to the location of an installed wind-turbine.

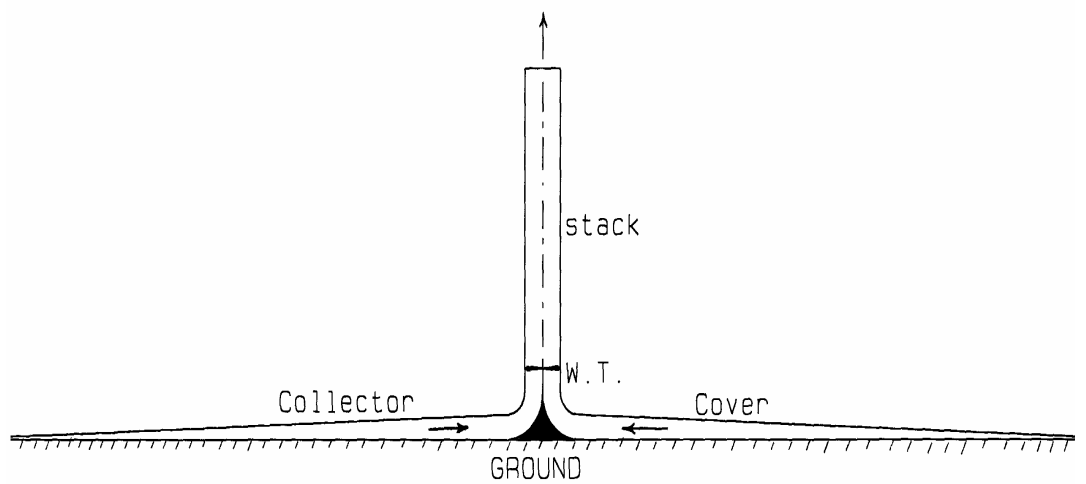

Figure 1: Conventional solar chimney plant.

Solar radiation penetrates the collector roof to warm the collector bottom, by virtue of the so called "green-house effect". The latter warms the air immediately above it, which then rises inside the chimney stack driven by buoyancy forces, and creating a partial vacuum near the ground surface.

The difference in pressure between the outside atmospheric air and the low pressure below the chimney stack causes the outside air to be drawn into the collector and towards the stack. Upon reaching the stack the air turns upwards and flows towards the stack outlet, driving an enclosed wind turbine along its way. The turbine is an axial pressure-staged one, more akin to Kaplan hydraulic turbines than to common wind turbines.

The performance of solar chimney plants has been investigated by several researchers [1-5]. Among others, Serag-Eldin [6] has shown that, for a given collector area, the performance increases rapidly with increase of height of stack. This is why commercial designs consider stack heights of $500-1000 \mathrm{~m}$. Technological difficulties and high costs restrict stack heights above this level.

\subsection{Proposed solar chimney mountain design}

Given a proposed solar chimney site in the northern hemisphere which features a nearby northern highly sloped mountain; considerable advantages may be gained by locating the collector in the valley immediately adjacent to the mountain side 
and replacing the chimney with a duct running upwards along the sloped side of the mountain, following the shortest convenient path towards the mountain top. In the southern hemisphere, a southern mountain is the preferred choice.

The duct should display a smooth progression from the collector crosssection into a horizontal tube (shaft), necessary to accommodate a horizontal axis wind-turbine, and then evolve into any arbitrary shape, optimized to cut construction costs and reduce flow losses. Obviously in this case the collector cover and absorber plate will no longer be circular, and they have to be shaped for optimum land usage and minimum flow losses, as will be revealed later on for the demonstration case. The duct may be built over the ground surface of the valley and mountain; however, to cut down costs, and or possibly mitigate environmental hazards, the duct could even be built as an underground tunnel or covered trench. Aesthetic considerations may also favour burying it.

Although the success of the design is highly site specific, so are many types of renewable energy systems; wind energy and tidal energy being notorious examples. Moreover, many potential sites may be found that meet the criteria.

\section{Mathematical model}

The model comprises three dimensional differential equations expressing the conservation of mass and energy, balance of momentum, and transport of the kinetic energy of turbulence, $\mathrm{k}$, and its rate of dissipation, $\varepsilon$, according to the $(\mathrm{k}-\varepsilon)$ model of turbulence, Launder and Spalding [7]. Employing the Cartesian system of coordinates $(\mathrm{x}, \mathrm{y}, \mathrm{z})$ the governing equations may all be cast in the following concise form:

$$
\nabla \cdot(\rho \underline{\mathrm{V}} \phi)=\nabla \cdot\left(\Gamma_{\phi} \nabla \phi\right)+\mathrm{S}_{\phi}
$$

where $\nabla \equiv \partial / \partial \mathrm{x} \underline{\mathrm{i}}+\partial / \partial \mathrm{y} \underline{\mathrm{i}}+\partial / \partial \mathrm{z} \underline{\mathrm{k}}$ is the Nabla operator, $\phi$ denotes any dependent variable, $\underline{\mathrm{V}}=\mathrm{u} \underline{\mathrm{i}}+\mathrm{v} \mathrm{j}+\mathrm{w} \underline{\mathrm{k}}$ is the velocity vector, $\Gamma_{\phi}$ and $\mathrm{S}_{\phi}$ are the diffusion coefficient and source term, respectively, for the variable $\phi$.

The mass conservation equation may also be expressed in the form of eqn (1) with $\phi \equiv 1$ and $\Gamma_{\phi}=S_{\phi}=0$. For the velocity components $\Gamma_{\phi}=\mu_{\mathrm{e}}$, whereas $\Gamma_{\mathrm{h}}=\mu_{\mathrm{t}} / \sigma_{\mathrm{h}}, \Gamma_{\mathrm{k}}=\mu_{\mathrm{t}} / \sigma_{\mathrm{k}}$ and $\Gamma_{\varepsilon}=\mu_{\mathrm{t}} / \sigma_{\varepsilon}$. The $\mathrm{S}_{\phi}$ expressions are presented in Table.1, where $\mathrm{p}$ denotes the static pressure; $\mu_{\mathrm{e}}$ is the effective viscosity, $\mu$ is the molecular viscosity, and $\mu_{\mathrm{t}}$ is the eddy diffusivity.. The turbulence model constants $\mathrm{C}_{1}, \mathrm{C}_{2}, \mathrm{C}_{\mu}, \sigma_{\mathrm{k}}, \sigma_{\varepsilon}$ and $\sigma_{\mathrm{h}}$ are those proposed by Launder and Spalding [7].

The local air-density, $\rho$, is calculated from the ideal gas equation of state, employing the standard atmospheric pressure and the locally computed air temperature. The latter is deduced from the solved for static enthalpy, h, of the air. The external prevailing air density, $\rho_{\mathrm{a}}$, is assumed constant and calculated according to the ideal gas equation of state at standard atmospheric pressure and the prevailing atmospheric temperature at ground level. 
Table 1: $\quad$ Source term expressions.

\begin{tabular}{|l|l|}
\hline$\phi$ & $\mathrm{S}_{\phi}$ \\
\hline $\mathrm{u}$ & $-\partial \mathrm{p} / \partial \mathrm{x}+\partial\left(\mu_{\mathrm{e}} \partial \mathrm{u} / \partial \mathrm{x}\right) / \partial \mathrm{x}+\partial\left(\mu_{\mathrm{e}} \partial \mathrm{v} / \partial \mathrm{x}\right) / \partial \mathrm{y}+\partial\left(\mu_{\mathrm{e}} \partial \mathrm{w} / \partial \mathrm{x}\right) / \partial \mathrm{z}$ \\
\hline $\mathrm{v}$ & $-\partial \mathrm{p} / \partial \mathrm{y}+\partial\left(\mu_{\mathrm{e}} \partial \mathrm{u} / \partial \mathrm{y}\right) / \partial \mathrm{x}+\partial\left(\mu_{\mathrm{e}} \partial \mathrm{v} / \partial \mathrm{y}\right) / \partial \mathrm{y}+\partial\left(\mu_{\mathrm{e}} \partial \mathrm{w} / \partial \mathrm{y}\right) / \partial \mathrm{z}+\left(\rho_{\mathrm{a}}-\rho\right) \mathrm{g}$ \\
\hline $\mathrm{w}$ & $-\partial \mathrm{p} / \partial \mathrm{z}+\partial\left(\mu_{\mathrm{e}} \partial \mathrm{u} / \partial \mathrm{z}\right) / \partial \mathrm{x}+\partial\left(\mu_{\mathrm{e}} \partial \mathrm{v} / \partial \mathrm{z}\right) / \partial \mathrm{y}+\partial\left(\mu_{\mathrm{e}} \partial \mathrm{w} / \partial \mathrm{z}\right) / \partial \mathrm{z}$ \\
\hline $\mathrm{k}$ & $\mathrm{G}_{\mathrm{k}}{ }^{*}+\mathrm{G}_{\mathrm{b}}{ }^{* *}-\rho \varepsilon$ \\
\hline$\varepsilon$ & $\mathrm{C}_{1} \varepsilon / \mathrm{k}\left(\mathrm{G}_{\mathrm{k}}{ }^{*}+\mathrm{G}_{\mathrm{b}}{ }^{* *}\right)-\mathrm{C}_{2} \rho \varepsilon^{2} / \mathrm{k}$ \\
\hline $\mathrm{h}$ & $\mathrm{D}^{\mathrm{D} / \mathrm{Dt}}$ \\
\hline${ }^{*} \mathrm{G}_{\mathrm{k}}=\mu_{\mathrm{t}}\left\{2\left[(\partial \mathrm{u} / \partial \mathrm{x})^{2}+(\partial \mathrm{v} / \partial \mathrm{y})^{2}+(\partial \mathrm{w} / \partial \mathrm{z})^{2}\right]+(\partial \mathrm{u} / \partial \mathrm{y}+\partial \mathrm{v} / \partial \mathrm{x})^{2}+(\partial \mathrm{u} / \partial \mathrm{z}+\partial \mathrm{w} / \partial \mathrm{x})^{2}\right.$ \\
\\
$\left.{ }^{* *} \mathrm{G}_{\mathrm{b}}=-\mu_{\mathrm{t}} / \sigma_{\mathrm{h}}\{\mathrm{g} / \partial \mathrm{z}+\partial \mathrm{w} / \partial \mathrm{y})^{2}\right\}, \quad$ where $\left.\mu_{\mathrm{t}} \equiv \rho \mathrm{C}_{\mu} \mathrm{k}^{2} / \varepsilon, \mu_{\mathrm{e}}=\mu+\mu_{\mathrm{t}} / \partial \mathrm{z}\right\}$ \\
\hline
\end{tabular}

The governing equations presented here adopt the Cartesian system of coordinates for sake of clarity and simplicity. However, the equations actually solved are the counterparts of the above in boundary-fitted-coordinates, BFC, Hedberg et al. [8]. The coordinate system is selected such that one of the coordinates tracks the local flow direction closely, while the other two coordinates are nearly orthogonal to it. The advantages of using this system are both accurate presentation of the boundary geometry, and minimization of numerical diffusion effects caused by the oblique intersection of local flow direction with grid-line directions.

The axi-symmetric counterpart of this model was reported in detail for a conventional solar chimney plant, by Serag-Eldin [6, 9]. Here, by necessity, three boundary fitted coordinates are employed. The wind-turbine is introduced as an actuator disk and its effect on the flow is introduced primarily as a drag force.

\section{Demonstration case}

The demonstration case is sketched in Fig. 2. It displays an approximately semicircular solar collector of $2000 \mathrm{~m}$ radius. The height of the collector cover at inlet is $8 \mathrm{~m}$ and it increases gradually towards the centre of the collector. The outlet of the collector develops gradually into a rectangular cross-section, $60 \mathrm{~m}$ high by $160 \mathrm{~m}$ wide, at a distance of $3200 \mathrm{~m}$ downstream the inlet. It develops further into a circular cross-section of $80 \mathrm{~m}$ diameter. The later forms the inlet of a $300 \mathrm{~m}$ long tube (shaft) which harbours the wind-turbine.

Downstream the turbine shaft, the duct forms a $45^{\circ}$ vertical bend and rises up the mountain side at an inclination of $45^{\circ}$. Right after the bend the cross- 
section develops gradually from the circular cross-section into a rectangular one of $42 \mathrm{~m}$ height and $120 \mathrm{~m}$ width. Thereafter, the rectangular duct continues to expand laterally and linearly to reach a width of $360 \mathrm{~m}$ at exit. The height of the duct centre-line at exit is approximately $1000 \mathrm{~m}$ above ground level. Three different exit section heights were considered; namely $14 \mathrm{~m}, 42 \mathrm{~m}$ and $84 \mathrm{~m}$. They correspond to constant area, a three folds and six folds increase, respectively.

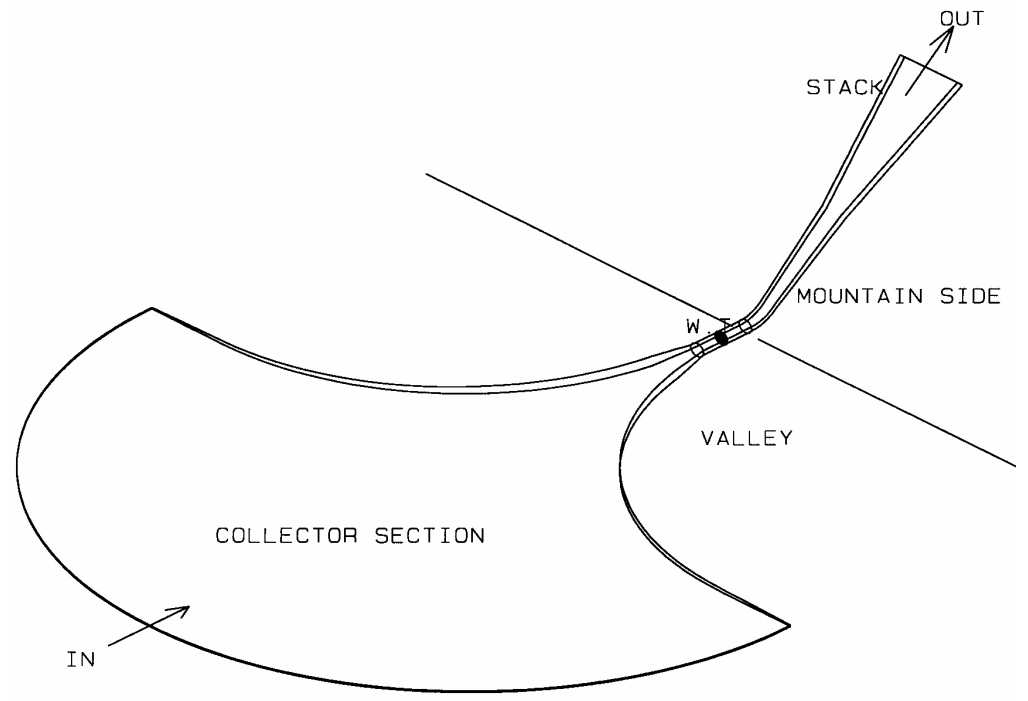

Figure 2: Sketch of proposed solar chimney design for mountainous regions.

\section{Results}

Figure 3 reveals part of the predicted velocity vectors in the collector region, midway up the collector-cover height. The vectors reveal in both magnitude and direction the predicted local velocity, the magnitude being revealed by the displayed arrow scale at the bottom of the diagram. The computational grid covered one half of symmetry plane, employing 20x40x106 cells in the quasi vertical, cross-stream and flow directions, respectively.

The vector shows that the external air is sucked in smoothly; and that with the exception of a narrow region close to the wall towards the collector exit, the flow is smooth. It is remarked that although the main bulk of the collector area is axi-symmetric, the flow arriving from the symmetry plane and that arriving from the near wall follow very different paths as they approach the exit of the collector; the former follows a straight-through path, whereas the latter goes through a $90^{\circ}$ bend. More careful design of the wall profile should eliminate this problem; at present the wall profile is simply taken to be an arc of a circle. 
It is also noted that the velocity magnitude is small throughout most of the collector region $(\sim 2 \mathrm{~m} / \mathrm{s})$ in order to minimize losses, but then accelerates rapidly as it approaches the turbine tunnel.

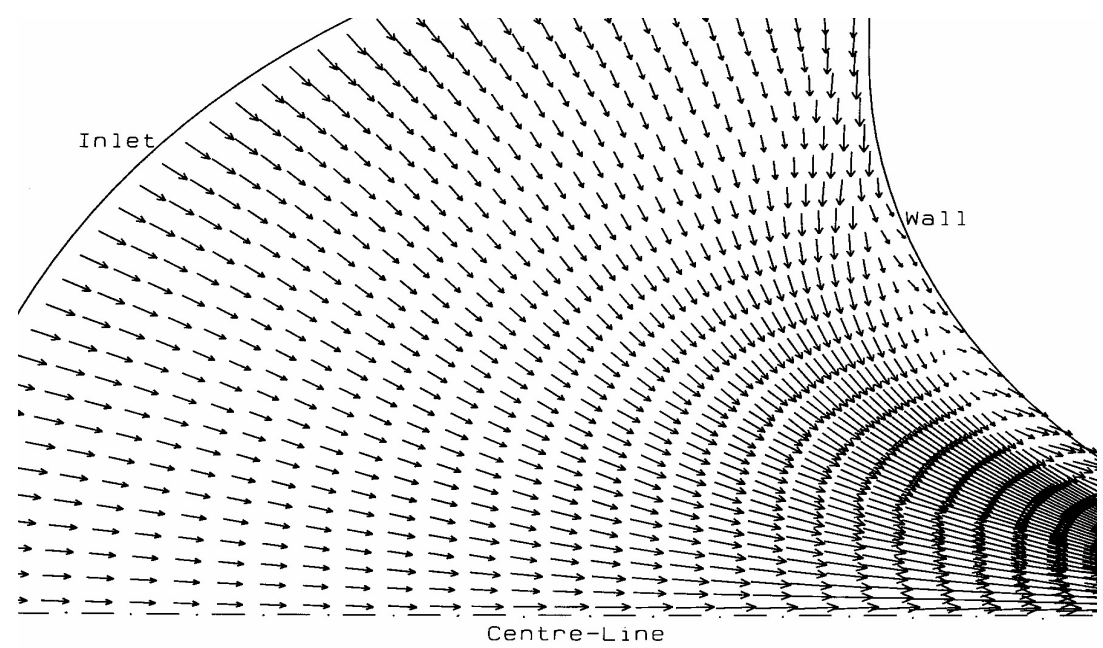

Figure 3: Velocity vectors at mid-plane of collector region.

Figure 4 reveals the corresponding velocity vectors in the far downstream region where the duct width expands linearly. The arrow scale now displays a velocity of $75 \mathrm{~m} / \mathrm{s}$, reflecting the much larger velocity magnitudes leaving the turbine shaft. The area ratio for the case displayed was three.

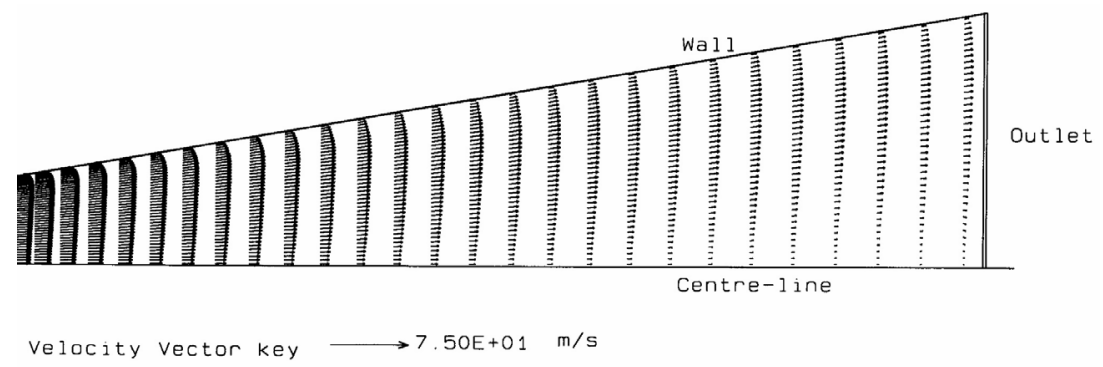

Figure 4: Velocity vectors in the far downstream section.

Figure 5 reveals the temperature distribution at ground level throughout the solar chimney plant. The ground level is horizontal up to the end of the turbine shaft, after which it rises with a slope of $45^{\circ}$ to follow the mountain side profile. A colour code is employed to differentiate between regions of same temperature 
range; the key on the right reveals their magnitudes. It is seen that with the exception of a narrow segment close to the side wall, the temperature distribution is nearly symmetrical. This is desired since it leads to more uniform temperature distributions and hence flow distribution at the turbine section. Near the walls temperatures are seen to be lower, influenced by heat loss from the side walls.

The temperature of the fluid is seen to rise as it flows towards the exit of the collector due to the continuous heating from the ground and the absence of re-circulatory motions. Good mixing results in near uniform temperature distribution at the wind turbine section (W.T.)

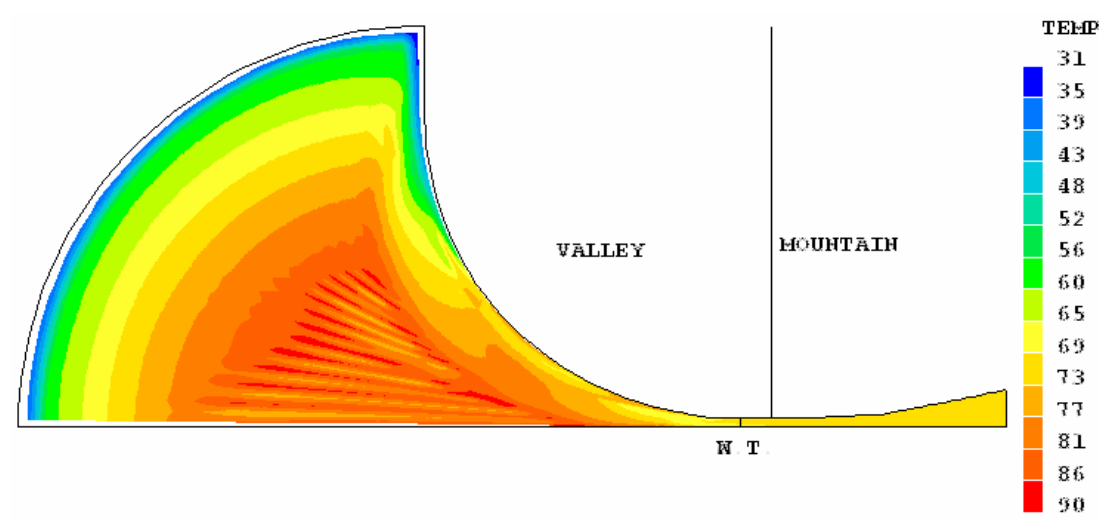

Figure 5: Temperature distribution at ground level.

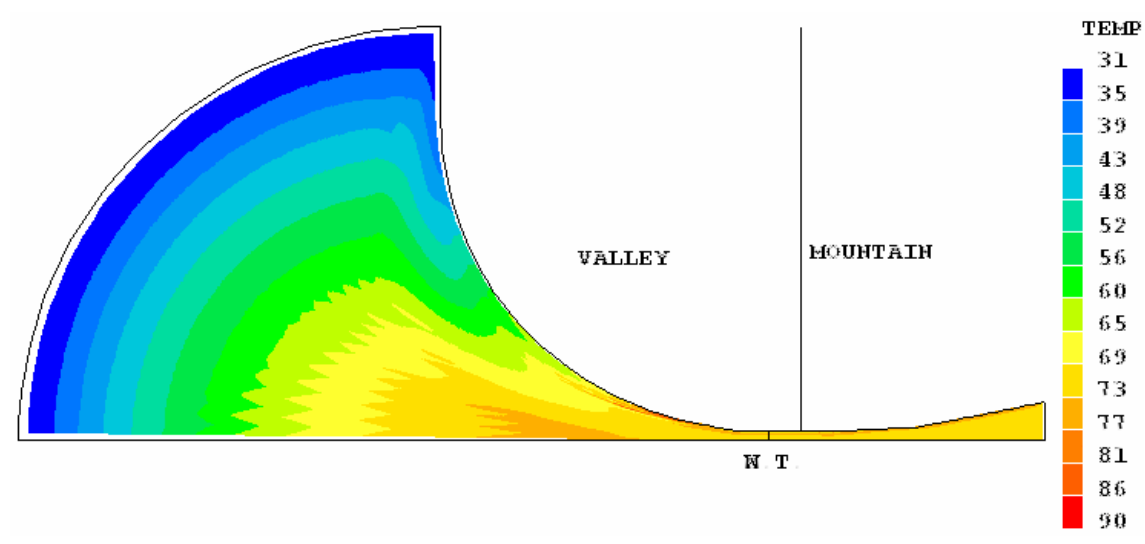

Figure 6: Temperature distribution half-way above ground.

Figure 6 reveals the corresponding temperature distribution at a solution surface half way up the duct cross-section; as expected the profiles reveal lower maximum temperatures and results of good mixing at the turbine plane. 
Figure 7 displays the "reduced-pressure" distribution over the vertical plane passing through the symmetry axis. The "reduced-pressure" refers to the difference between the local pressure and the external atmospheric pressure at the same horizontal height; which is the quantity actually solved for in order to simplify boundary conditions. A colour code is employed to reveal the reduced pressure levels. A large pressure drop is noticed at the turbine section (W.T.), and kinetic energy recovery is apparent in the diffuser section.

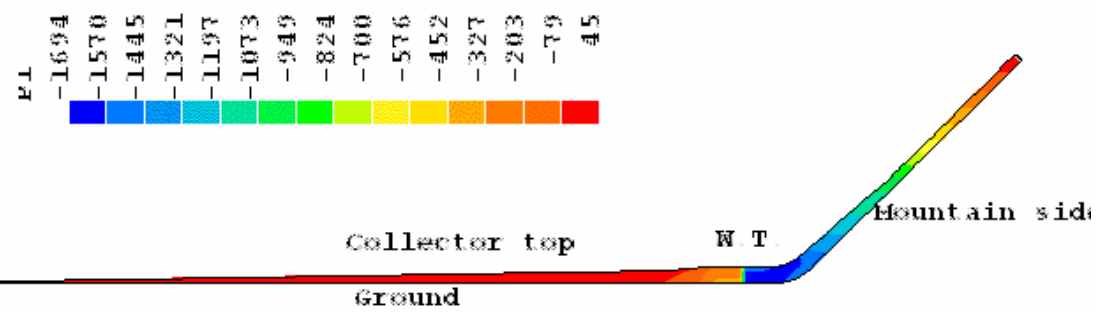

Figure 7: $\quad$ Reduced pressure distribution in vertical symmetry plane.

The effect of stack area-ratio on output of turbine is displayed in Fig. 8. Power output is estimated as the product of mean axial velocity at turbine section and total turbine thrust (drag) force. It is apparent that a $20 \%$ gain in output can be obtained by introducing an area ratio of three; however, further increase leads only to small gains.

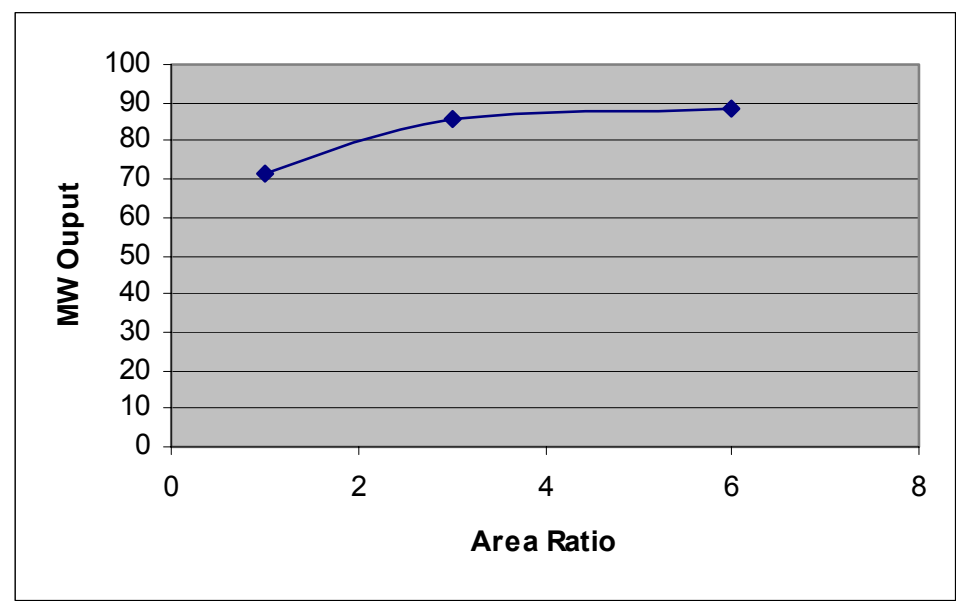

Figure 8: $\quad$ Effect of exit area-ratio on output. 


\section{Advantages of proposed design}

When an appropriate terrain is encountered, the proposed design offers the following advantages over the conventional solar chimney design:

\subsection{Cost savings}

It is expected that the exhaust duct, which is supported directly on the ground will be much cheaper to build than a towering chimney stack, over $500 \mathrm{~m}$ high. Moreover the wind turbine will be located much closer to the ground, thus cutting down the cost of its support structure.

\subsection{Potential for higher heads}

Due to structural concerns, particularly those related to wind loads and seismic loads, the current technology limits feasible chimney stack heights to under $1000 \mathrm{~m}$. With the present design considerably higher heights may be reached, the only limitation being posed by the height of the mountain peak. Indeed, this could also be extended partially, by building a chimney stack at the top of the mountain peak.

\subsection{Less need for sophisticated technology}

Solar chimney power plants have been presented as an ideal energy source for many of the developing countries lying in the solar belt (Schlaich and Schiel [10]). Except for the towering chimney stack, they require only primitive technology to build. The new design dispenses with the technologically challenging stack, and therefore local expertise may be all that is needed.

\subsection{Potential for co-generation and combined cycle}

One of the major disadvantages of solar chimney plants is their very low efficiency. Most of the solar energy used to heat the air is wasted in the form of hot air exhausting from the stack to the atmosphere. With the present design, the hot air may be employed at the top of the mountain for cogeneration or combined cycle purposes.

\subsection{Kinetic energy recovery}

Another source of energy waste in conventional solar chimney plants is the kinetic energy of the exhausting air. For economic reasons the exit stack diameter is kept to a minimum and thus exhaust air leaves at substantial velocities. However, with the present design it is fairly economic and very feasible to build a diffuser section in the exhaust duct to reduce the kinetic energy loss. 


\section{Summary and conclusions}

The paper proposes exploiting the height of appropriate nearby mountains to replace the costly chimney stack with a simple ground laid duct. This offers many advantages in terms of economy as well as potential for cogeneration and combined cycle applications. A demonstration case is presented and the concept is validated employing a given computational model. Although each design will necessarily be site specific, the design may be readily optimized with the aid of the presented computational model.

\section{References}

[1] Padki, M.M. \& Sherif, S.A., On a simple analytical model for solar chimneys," Int. J. Energy Research, 23(4), pp. 345-349, 1999.

[2] VonBackstrom, T.W.\& Gannon, A.J., Compressible flow through solar power plant chimneys," ASME J. Solar Energy Eng.,122(3), pp.138-145, 2000.

[3] Pasumarthi, N. \& Sherif, S.A., Performance of a demonstration solar chimney model for power generation, Proc. $35^{\text {th }}$ Heat Transfer and Fluid Mechs. Inst., ed. F.H. Reardon, Sacremento, California, 1997.

[4] Gannon, A.J. \& Von Backstrom, T.W., Solar chimney cycle analysis with system loss and solar collector performance, J. Solar Energy Eng., 122, pp.133-137, 2000.

[5] Serag-Eldin, M.A., Computing flow in a solar chimney plant subject to atmospheric winds", Proc. ASME Heat Transfer/Fluids Engineering Summer Conference, Charlotte, NC, 2004.

[6] Serag-Eldin, M.A., Analysis of effect of geometric parameters on performance of solar chimney plants, Proc. ASME 2005 Summer Heat Transfer Conference, San Francisco, CA, HT2005-72340, 2005.

[7] Launder, B.E. and Spalding, D.B., The numerical computation of turbulent flows, J. Computer Methods in Applied Mechanics and Eng., 3(1), pp. 269-289, 1974.

[8] Hedberg, P.K., Rosten, H.I. and Spalding, D.B., The PHOENICS Equations, Report TR/99, CHAM , U.K., 1986.

[9] Serag-Eldin, M.A., Analysis of effect of turbine characteristics on performance of solar chimney plants, Proc. ASME 2005 Summer HT Conf., San Francisco, CA, Paper No. HT2005-72835, 2005.

[10] Schlaich, J. and Schiel,W., Solar Chimneys, Encyclopaedia of Physical Science and Technology, pp1-10, ${ }^{\text {rd }}$, edition, 2000. 